\title{
Órgãos internos e trato gastrintestinal de novilhos de gerações avançadas do cruzamento rotativo entre as raças Charolês e Nelore terminados em confinamento
}

\author{
Luís Fernando Glasenapp de Menezes ${ }^{1}$, João Restle ${ }^{2}$, Ivan Luiz Brondani ${ }^{3}$, Fernando Kuss ${ }^{4}$, \\ Dari Celestino Alves Filho ${ }^{5}$, Magali Floriano da Silveira ${ }^{6}$, Daniel Terra Leite ${ }^{6}$

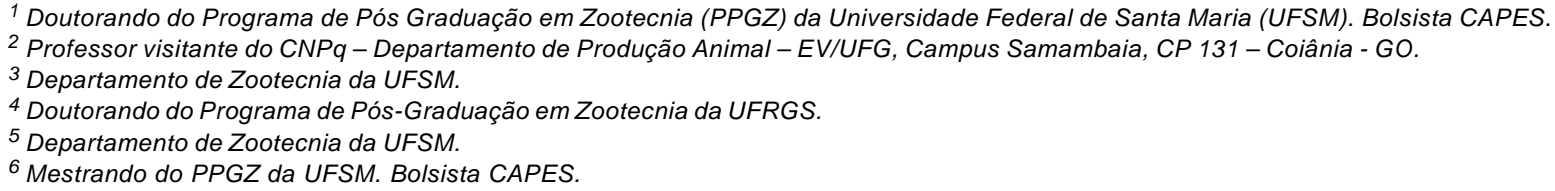

RESUMO - Foram avaliados os efeitos de heterose e de grupo genético nos órgãos internos e no trato gastrintestinal de novilhos puros (Charolês - C e Nelore - N) e cruzados da segunda (G2) (3/4C 1/4N e 3/4N 1/4C), terceira (G3) (5/8C 3/8N e $5 / 8 \mathrm{~N} 3 / 8 \mathrm{C})$ e quarta $(\mathrm{G} 4)(11 / 16 \mathrm{C} 5 / 16 \mathrm{~N}$ e $11 / 16 \mathrm{~N} 5 / 16 \mathrm{C})$ gerações de cruzamento terminados em confinamento e abatidos com 23 meses de idade. Os animais cruzados da G2, G3 e G4 foram, respectivamente, 14,95; 17,25 e 18,46\% superiores aos puros quanto ao peso de corpo vazio (PCVZ). A heterose para o rendimento de carcaça fria em relação ao PCVZ (RCFCVZ) foi positiva em todas as gerações. Os mestiços apresentaram menor peso relativo (ao PCVZ) de coração, pulmões e rins, de modo que a heterose foi significativa para peso de coração $(-18,29 \%)$ e rins $(-14,29 \%)$ na G3 e para pulmões $(-13,45 \%)$ na G4. Novilhos mestiços apresentaram valores inferiores à média dos puros para todos os componentes do trato gastrintestinal quando o peso destes componentes foi expresso em relação a $100 \mathrm{~kg}$ de PCVZ ou de peso vivo ao abate (PVA), com exceção do rúmen na G2. A heterose retida foi positiva e significativa para PCVZ, RCFCVZ e para peso absoluto do fígado. Entretanto, foi negativa para a quantidade de sangue para os pesos de coração, intestino delgado + grosso e trato gastrintestinal quando expressos em relação a $100 \mathrm{~kg}$ de PCVZ e de PVA. Entre os animais puros, os novilhos Nelore tiveram maior RCFCVZ (57,09 vs $61,64 \%)$. O peso absoluto de rúmen, abomaso, intestino delgado + grosso e o trato gastrintestinal foram maiores nos novilhos Charolês em relação aos Nelore, o que também foi observado quando estes componentes foram expressos em relação ao PCVZ e PVA, com exceção para o intestino grosso + delgado. Estas diferenças explicam, em parte, o maior rendimento de carcaça dos novilhos Nelore.

Palavras-chave: Bos indicus, Bos taurus, cruzamento, heterose, peso de corpo vazio

\section{Internal organs and gastrointestinal tract of feedlot finished steers of advanced generations of rotational crossbreeding between Charolais and Nellore}

\begin{abstract}
The objective of this trial was to investigate the effect of heterosis and genetic group on the yield and weight of internal organs and gastrointestinal tract (GIT) of feedlot purebred (Charolais - C and Nellore $-\mathrm{N}$ ) and crossbred steers from second $(\mathrm{G} 2)(3 / 4 \mathrm{C} 1 / 4 \mathrm{~N}$ and $3 / 4 \mathrm{~N} 1 / 4 \mathrm{C})$, third $(\mathrm{G} 3)(5 / 8 \mathrm{C} 3 / 8 \mathrm{~N}$ and $5 / 8 \mathrm{~N} 3 / 8 \mathrm{C})$ and fourth $(\mathrm{G} 4)(11 / 16 \mathrm{C} 5 / 16 \mathrm{~N}$ and $11 / 16 \mathrm{~N} \mathrm{5/16C)}$ generations of rotational crossbreeding slaughtered at 23 month of age. Crossbred steers from G2, G3 and G4 had, respectively, 14.95, 17.25 and $18.46 \%$ higher empty body weight (EBW) than that from purebred animals. A positive heterosis for cold carcass yield expressed as a proportion of EBW (CCYEBW) was observed in G2, G3, and G4. Weights of heart, lungs, and kidneys adjusted for EBW were lower on crossbred compared to purebred steers; the heterosis was significant for the weights of heart (-18.29\%) and kidneys (-14.29\%) in G3 and for that of lungs (-13.45\%) in G4. Weights of all organs of the GIT either expressed as $100 \mathrm{~kg}$ of EBW or as proportion of slaughter body weight (SBW) were lower on crossbred than on purebred steers with the exception of rumen weight in G2. Retained heterosis was positive and significant for EBW, CCYEBW and liver weight. However, it was negative for amount of blood and weights of heart and small plus large intestines when expressed as $100 \mathrm{~kg}$ of EBW and SBW. Within purebred animals, N showed greater CCYEBW (61.64\%) than C (57.09). Conversely, weights of rumen, abomasum, small plus large intestine, and GIT were all higher on $\mathrm{C}$ than $\mathrm{N}$ steers; excepting for small plus large intestine, the same was observed when weights of the remaining GIT components were expressed as proportion of EBW and SB. These differences partially explain the increased carcass yield on $\mathrm{N}$ steers.
\end{abstract}

Key Words: Bos indicus, Bos Taurus, crossbreeding, heterosis, heterozygosis, empty body weight 


\section{Introdução}

Os grupos genéticos bovinos encontrados no Brasil, especialmente na Região Sul, são muito variados, pois muitos criadores ainda escolhem as raças pela preferência pessoal, ou por modismo, em detrimento da escolha pela produtividade. Para escolha da raça mais produtiva para cada situação, o entendimento e domínio de vários aspectos como desempenho, composição de carcaça e exigências nutricionais são fundamentais. As diferenças genéticas são representadas pela variação do rendimento de carcaça e dos requerimentos nutricionais. Esta variação se deve, principalmente, às diferenças nos fatores relacionados às características das partes do corpo não-integrantes da carcaça.

Diferenças nos requerimentos, principalmente energéticos, estão associadas a variações nas atividades metabólicas dos órgãos, entre os quais, segundo Smith \& Baldwin (1973), o coração, o fígado e o trato gastrintestinal são os de maior atividade. Os tecidos viscerais consomem aproximadamente $50 \%$ da energia de mantença, enquanto os músculos gastam 23\% (Caton \& Dhuyvetter, 1997), diferença atribuída por Owens et al. (1993) ao maior tunorver protéico dos órgãos relacionados à digestão quando comparados ao músculo esquelético. Vários pesquisadores (Lunt et al., 1986; Solis et al., 1988) demonstraram que o peso do trato gastrintestinal e dos órgãos internos de animais zebuínos em relação aos taurinos e mestiços é menor, o que justifica a mais baixa exigência de mantença de animais zebuínos (NRC, 1996).

O rendimento de carcaça é uma característica muito importante para o sistema de produção nos últimos anos. Inicialmente, os bovinos eram comercializados com base no peso vivo, mas, gradativamente, a comercialização passou a ser feita com base no peso de carcaça. Restle et al. (1999) observaram que a introdução de animais Nelore nos cruzamentos aumentou linearmente o rendimento de carcaça. Esse maior rendimento de carcaça dos animais zebuínos pode ser atribuído aos menores pesos relativos das patas e do trato gastrintestinal dos animais deste genótipo (Peron et al., 1993a).

Além de influenciar as exigências energéticas dos animais e afetar o rendimento de carcaça, os componentes nãointegrantes da carcaça são importante fonte de receita para os frigoríficos que os comercializam tanto no mercado interno quanto no externo (Restle et al., 2005).

Diferenças nos pesos dos órgãos vitais, do sangue e do trato gastrintestinal em animais mestiços segundo a predominância taurina ou zebuína no genótipo são relatadas por Pacheco et al. (2005), em novilhos, e por Kuss et al. (2007), em vacas de descarte.
Neste experimento, objetivou-se avaliar o desenvolvimento dos órgãos internos de novilhos terminados em confinamento, puros e da segunda, terceira e quarta gerações do cruzamento rotativo entre as raças Charolês e Nelore.

\section{Material e Métodos}

O trabalho foi realizado no Setor de Bovinocultura de Corte do Departamento de Zootecnia da Universidade Federal de Santa Maria (UFSM). Comparou-se o efeito da composição racial e da heterose no desenvolvimento dos órgãos internos de novilhos puros Charolês (C) e Nelore (N) e mestiços da segunda $(\mathrm{G} 2)(3 / 4 \mathrm{C} 1 / 4 \mathrm{Ne} 3 / 4 \mathrm{~N} 1 / 4 \mathrm{C})$, terceira (G3) $(5 / 8 \mathrm{C} 3 / 8 \mathrm{~N} \mathrm{e} 5 / 8 \mathrm{~N} 3 / 8 \mathrm{C})$ e quarta $(\mathrm{G} 4)(11 / 16 \mathrm{C} 5 / 16 \mathrm{Ne}$ 11/16N 5/16C) gerações de cruzamento. A heterose considerada neste trabalho é a total, decorrente da heterozigose individual e materna.

Foram utilizados 57 novilhos tomados ao acaso da fazenda experimental da UFSM, nascidos na mesma época de parição e mantidos sempre sob as mesmas condições de manejo e alimentação. Os novilhos foram gerados por fêmeas puras e mestiças inseminadas com sêmen de seis touros de cada raça (Charolês e Nelore). Quatro touros de cada raça foram utilizados para repasse na monta a campo. Os touros Charolês que originaram os novilhos Charolês foram os mesmos que deram origem aos novilhos $3 / 4 \mathrm{C} 1 / 4 \mathrm{~N}$, $5 / 8 \mathrm{C} 3 / 8 \mathrm{Ne} 11 / 16 \mathrm{C} 5 / 16 \mathrm{~N}$, assim como os touros Nelore que geraram os novilhos Nelore foram os mesmos que geraram os novilhos 3/4N 1/4C, 5/8N 3/8C e 11/16N 5/16C.

Ao início do período de terminação em confinamento, os animais apresentavam, em média, 20 meses de idade e $304 \mathrm{~kg}$. O período total de confinamento teve duração de 97 dias, sendo que os primeiros 14 dias de confinamento foram destinados à adaptação ao confinamento e à dieta. A dieta, igual para todos os animais, foi calculada para proporcionar GMD de 1,2 kg (NRC, 1996) e apresentava $12,32 \%$ de PB, 2,96 Mcal de ED e 58,30\% de FDN. O volumoso, representando $52 \%$ da MS total, foi constituído de silagem de milho (AG 5011). O concentrado foi composto de $93,97 \%$ de farelo de trigo, $1,5 \%$ de uréia, $3,62 \%$ de calcário calcítico, $0,9 \%$ de sal e, ainda, monensina sódica em dose recomendada pelo fabricante.

Depois de 97 dias de confinamento, os animais foram pesados após jejum de sólidos de 14 horas e embarcados para um frigorífico comercial. $\mathrm{O}$ abate foi realizado logo na chegada, conforme o fluxo normal do estabelecimento. Foram tomados os pesos de cabeça, patas, sangue, couro, vassoura da cauda, retículo-rúmen, omaso, abomaso, intestino delgado, intestino grosso, coração, rins, fígado, pulmões, baço e gorduras internas (inguinal, renal, ruminal 
e de toalete). O peso de carcaça mais o somatório de todos esses componentes resultou no peso de corpo vazio.

As vísceras foram pesadas cheias e lavadas em água corrente para determinação do peso do conteúdo do trato gastrintestinal.

O delineamento experimental utilizado foi o inteiramente casualizado, com número diferenciado de repetições por grupo genético: seis repetições para os grupos $\mathrm{C}, 3 / 4 \mathrm{C}$ $1 / 4 \mathrm{~N}$ e $11 / 16 \mathrm{~N} 5 / 16 \mathrm{C}$; nove para os grupos $3 / 4 \mathrm{~N} 1 / 4 \mathrm{C}$ e $11 / 16 \mathrm{C} 5 / 16 \mathrm{~N} ; 12$ para o grupo $5 / 8 \mathrm{C} 3 / 8 \mathrm{~N}$; e 15 para os grupos $\mathrm{Ne} 5 / 8 \mathrm{~N} 3 / 8 \mathrm{C}$ ).

Os dados foram analisados por meio de análise de variância e as médias foram comparadas pelo procedimento pdiff (teste t), por meio do pacote estatístico SAS (1997), utilizando-se o seguinte modelo estatístico:

$$
\mathrm{Y}_{\mathrm{ijk}}=\mu+\mathrm{IV}_{\mathrm{k}}+\mathrm{SA}_{\mathrm{i}}+\mathrm{GG}_{\mathrm{j}}\left(\mathrm{SA}_{\mathrm{i}}\right)+\mathrm{E}_{\mathrm{ijk}}
$$

em que: $\mathrm{Y}_{\mathrm{ijkl}}=$ variáveis dependentes; $\mu=$ média de todas as observações; $\mathrm{IV}_{\mathrm{k}}=$ efeito da k-ésima idade da vaca, mãe do novilho; $\mathrm{SA}_{\mathrm{i}}=$ efeito do sistema de acasalamento de índice $i$, sendo $i=1$ (puros), 2 (mestiços da G2), 3 (mestiços da G3) e 4 (mestiços da G4); $\mathrm{GG}_{\mathrm{j}}\left(\mathrm{SA}_{\mathrm{i}}\right)=$ efeito do grupo genético de índice $\mathrm{j}$ aninhado dentro do sistema de acasalamento $i$, sendo $j=1$ (Charolês) e 2 (Nelore) dentro do SA $1 ; 1(3 / 4 \mathrm{C} 1 / 4 \mathrm{~N})$, e 2 (3/4N 1/4C) dentro do SA $2 ; 1$ (5/8 C $3 / 8 \mathrm{~N})$ e $2(5 / 8 \mathrm{~N} 3 / 8 \mathrm{C})$ dentro do SA 3 ; 1 (11/16C 5/16N) e $2(11 / 16 \mathrm{~N} 5 / 16 \mathrm{C})$ dentro do $\mathrm{SA} 4 ; \mathrm{E}_{\mathrm{ijkl}}=$ efeito aleatório residual.

Também foi calculada a heterose resultante das características avaliadas nas diferentes gerações de cruzamento:

$\mathrm{H} \%=[$ (média dos mestiços dentro de cada geração/ médias dos puros)-1] x 100

A heterose retida foi calculada por meio da seguinte equação:

$\mathrm{Hr} \%=[($ média de todos os mestiços/média dos puros $)-1]$ $\mathrm{x} 100$.

\section{Resultados e Discussão}

As médias e heteroses para peso (PCVZ) e rendimento (RCVZ) de corpo vazio, para rendimento de carcaça fria em relação ao PCVZ (RCFCVZ), para peso absoluto de sangue e em relação a $100 \mathrm{~kg}$ de PCVZ e a $100 \mathrm{~kg}$ de PV ao abate (PVA) são descritas na Tabela 1.

O PCVZ sofreu influência da heterozigose em todas as gerações, resultando em heterose de 14,95; 17,25 e 18,46\% na G2, G3 e G4, respectivamente.

A heterose para RCVZ foi significativa $(\mathrm{P}<0,05)$ apenas na terceira geração de cruzamento, observando-se que os animais desta geração apresentaram 4,36\% menos RCVZ que a média dos animais puros. Segundo Owens et al. (1995), várias equações de regressão foram criadas para estimar o peso corporal vazio por meio do peso vivo, sendo que o PCVZ correspondeu de 85 a $95 \%$ do peso corporal. Neste estudo, esta relação variou de $85,44 \%$ (animais $11 / 16 \mathrm{C} 5 / 16 \mathrm{~N}$ ) a $93,16 \%$ (animais 3/4C 1/4N). Segundo Lana et al. (1992), as diferenças entre o peso corporal e o PCVZ diminuíram à medida que o peso PCVZ elevou, principalmente em decorrência da diminuição no conteúdo gastrintestinal. Neste estudo, a correlação entre o peso vivo em jejum e o PCVZ foi de 0,93 ( $\mathrm{P}<0,01)$.

A heterose para RCFCVZ foi positiva em todas as gerações de cruzamento e acompanhou a flutuação do grau de heterozigose, de $50 \%$ na G2, 75\% na G3 e 68,75\% na G4. O efeito da heterozigose no RCFCVZ foi significativo na 3 a e 4a gerações do cruzamento, de modo que os novilhos mestiços apresentaram, respectivamente, 7,90 e 5,68\% mais rendimento de carcaça fria que a média dos puros. A heterose retida foi significativa e representou diferença de $5,54 \%$ no RCFCVZ. Entre os animais puros, houve superioridade $(\mathrm{P}<0,10)$ de $7,97 \%$ no rendimento dos novilhos Nelore. $\mathrm{Na}$ G2 e G3, houve superioridade numérica $(P>0,10)$ para os novilhos com maior predominância de Nelore, comprovando que este genótipo tem efeito genético aditivo para esta característica, como constatado por Restle et al. (1999). No entanto, na G4 os novilhos 11/16C 5/16N foram superiores $(\mathrm{P}<0,05)$ aos $11 / 16 \mathrm{~N} 5 / 16 \mathrm{C}$ para esta característica.

Apesar do maior peso corporal, os animais cruzados apresentaram, em todas as gerações, menor quantidade de sangue, porém, a diferença foi significativa apenas na G2, quando a quantidade de sangue foi expressa em relação ao PCVZ. A heterose retida foi significativa quando a quantidade de sangue foi expressa em relação ao PCVZ e ao PVA. Não houve diferença significativa na quantidade de sangue entre novilhos $\mathrm{CeN}$, embora numericamente esta quantidade tenha sido maior nos novilhos C. Também não houve diferença significativa entre os genótipos com predominância $\mathrm{C}$ ou $\mathrm{N}$ nas diferentes gerações de cruzamento. No entanto, Kuss et al. (2007), avaliando vacas de descarte, e Pacheco et al. (2005), novilhos jovens, verificaram que a quantidade de sangue foi significativamente maior nos animais com predominância Charolês em relação àqueles com predominância Nelore no genótipo.

A menor quantidade de sangue no corpo dos animais mestiços foi um dos fatores que contribuiu para seu maior RCFCVZ. A correlação entre a quantidade de sangue e o RCFCVZ foi de -0,40 ( $\mathrm{P}<0,01)$. Ribeiro et al. (2001) relacionaram o tamanho dos órgãos à quantidade de sangue no corpo do animal, ou seja, quanto maior os órgãos, maior a 
Tabela 1 - Médias, erros-padrão e heterose para peso (PCVZ) e rendimento de corpo vazio (RCVZ), para rendimento de carcaça fria em relação ao PCVZ (RCFCVZ) e para peso de sangue absoluto e em relação a $100 \mathrm{~kg}$ de PCVZ e ao peso vivo ao abate (PVA) de novilhos de diferentes grupos genéticos

Table 1 - Means, standard errors and heterosis for empty body weight (EBW), empty body weight yield (EBWY), cold carcass yield as proportion of EBW (CCYEBW), blood weight and blood weight expressed as $100 \mathrm{~kg}$ of EBW and slaughter body weight (SBW) of steers according to different genetic groups

\begin{tabular}{|c|c|c|c|c|c|c|}
\hline $\begin{array}{l}\text { Grupo genético } \\
\text { Genetic group }\end{array}$ & $\begin{array}{l}\mathrm{PCVZ}, \mathrm{kg} \\
\quad E B W\end{array}$ & $\begin{array}{l}\mathrm{RCVZ} \% \\
E B W Y\end{array}$ & $\begin{array}{l}\text { RCFCVZ,\% } \\
\text { CCYEBW }\end{array}$ & $\begin{array}{l}\text { Sangue, } \mathrm{kg} \\
\text { Blood, } \mathrm{kg}\end{array}$ & $\begin{array}{l}\text { Sangue, \% do PCVZ } \\
\text { Blood, \% of EBW }\end{array}$ & $\begin{array}{l}\text { Sangue, \% do PVA } \\
\text { Blood, \% of } S B W\end{array}$ \\
\hline Charolês (C) & $367,2 \pm 26,3^{\mathrm{a}}$ & $91,74 \pm 2,3$ & $57,09 \pm 1,8^{\mathrm{d}}$ & $24,44 \pm 3,31$ & $6,59 \pm 0,90$ & $6,06 \pm 0,89$ \\
\hline Nelore $(\mathrm{N})$ & $315,7 \pm 22,7^{b}$ & $90,99 \pm 2,0$ & $61,64 \pm 1,6^{\mathrm{c}}$ & $17,58 \pm 2,89$ & $5,74 \pm 0,79$ & $5,25 \pm 0,78$ \\
\hline Média puros & $341,5 \pm 16,7$ & $91,37 \pm 1,3$ & $59,37 \pm 1,1$ & $21,01 \pm 2,10$ & $6,16 \pm 0,57$ & $5,66 \pm 0,56$ \\
\hline \multicolumn{7}{|l|}{ Straigthbred mean } \\
\hline $3 / 4 \mathrm{C} 1 / 4 \mathrm{~N}$ & $394,3 \pm 23,0$ & $93,16 \pm 2,0$ & $59,86 \pm 1,6$ & $15,85 \pm 2,89$ & $4,02 \pm 0,79$ & $3,77 \pm 0,78$ \\
\hline $3 / 4 \mathrm{~N} 1 / 4 \mathrm{C}$ & $390,7 \pm 18,9$ & $88,64 \pm 1,6$ & $62,49 \pm 1,3$ & $19,79 \pm 2,38$ & $5,09 \pm 0,65$ & $4,54 \pm 0,64$ \\
\hline Média G2 & $392,5 \pm 14,8$ & $90,90 \pm 1,3$ & $61,18 \pm 1,0$ & $17,82 \pm 1,86$ & $4,55 \pm 0,51$ & $4,15 \pm 0,50$ \\
\hline \multicolumn{7}{|l|}{ G2 mean } \\
\hline Heterose G2, \% & $14,95 * *$ & $-0,51$ & 3,05 & $-15,18$ & $-26,12 *$ & $-26,53$ \\
\hline \multicolumn{7}{|l|}{ G2 heterosis, \% } \\
\hline $5 / 8 \mathrm{C} \quad 3 / 8 \mathrm{~N}$ & $393,2 \pm 14,7$ & $88,03 \pm 1,4$ & $63,81 \pm 1,1$ & $20,89 \pm 2,38$ & $5,23 \pm 0,57$ & $4,63 \pm 0,56$ \\
\hline $5 / 8 \mathrm{~N} 3 / 8 \mathrm{C}$ & $407,5 \pm 12,7$ & $86,73 \pm 1,2$ & $64,30 \pm 0,9$ & $20,41 \pm 2,07$ & $4,99 \pm 0,50$ & $4,36 \pm 0,49$ \\
\hline Média G3 & $400,4 \pm 9,4$ & $87,38 \pm 0,9$ & $64,06 \pm 0,7$ & $20,65 \pm 1,54$ & $5,11 \pm 0,37$ & $4,50 \pm 0,36$ \\
\hline \multicolumn{7}{|l|}{ G3 mean } \\
\hline Heterose G3, \% & $17,25^{*}$ & $-4,36 * *$ & $7,90 * * *$ & $-1,71$ & $-17,11$ & $-20,51$ \\
\hline \multicolumn{7}{|l|}{ G3 heterosis, \% } \\
\hline $11 / 16$ C $5 / 16 \mathrm{~N}$ & $421,4 \pm 14,1$ & $85,44 \pm 1,7^{b}$ & $65,09 \pm 1,3^{\mathrm{a}}$ & $20,22 \pm 2,33$ & $4,74 \pm 0,70$ & $4,04 \pm 0,69$ \\
\hline $11 / 16 \mathrm{~N} 5 / 16 \mathrm{C}$ & $387,5 \pm 15,8$ & $92,19 \pm 1,9^{a}$ & $60,40 \pm 1,5^{b}$ & $21,52 \pm 2,62$ & $5,65 \pm 0,78$ & $5,22 \pm 0,77$ \\
\hline Média G4 & $404,5 \pm 10,9$ & $88,82 \pm 1,3$ & $62,74 \pm 1,0$ & $20,87 \pm 1,81$ & $5,20 \pm 0,54$ & $4,63 \pm 0,53$ \\
\hline \multicolumn{7}{|l|}{ G4 mean } \\
\hline $\begin{array}{l}\text { Heterose G4, \% } \\
\text { G4 heterosis }\end{array}$ & $18,46 * *$ & $-2,79$ & $5,68 *$ & $-0,67$ & $-15,73$ & $-18,13$ \\
\hline $\begin{array}{l}\text { Heterose retida, } \% \\
\text { Retained heterosis, } \%\end{array}$ & $16,89 *$ & $-2,55$ & $5,54 * *$ & $-5,85$ & $-19,65 * *$ & $-21,72 * *$ \\
\hline $\begin{array}{l}\text { Diferença mestiços e C, \% } \\
\text { Crossbreds and C difference, \% }\end{array}$ & $12,06 *$ & $-2,95$ & 9,76 & $-19,07$ & $-24,84$ & $-26,95$ \\
\hline $\begin{array}{l}\text { Diferença mestiços e N, \% } \\
\text { Crossbreds and } N \text { difference, \% }\end{array}$ & $29,88 * * *$ & $-2,15$ & 1,65 & 12,51 & $-13,70 *$ & $-15,68 *$ \\
\hline
\end{tabular}

$* * * \mathrm{P}<0,01 ; * * \mathrm{P}<0,05 ; \quad * \mathrm{P}<0,10$.

Médias, na coluna, seguidas por letras diferentes na comparação entre $\mathrm{C}$ e $\mathrm{N}$ ou entre os genótipos dentro da mesma geração de cruzamento são diferentes $\left(\mathrm{P}<0,05(\mathrm{a}, \mathrm{b}) ; \mathrm{P}<0,10\left({ }^{\mathrm{c}, \mathrm{d}}\right)\right)$ pelo teste $\mathrm{t}$.

${ }^{* \star *} P<0.01 ;{ }^{* *} P<0.05 ;{ }^{*} P<0.10$.

Means, within a column, followed by different letters for comparison between $C$ and $N$, or between genotypes within the same crossbreeding generation differ $[P<0.05(a, b) ; P<0.10(c, d)]$ by $t$ test.

quantidade de sangue, possivelmente para suportar a maior taxa metabólica desses animais (Pacheco et al., 2005). Neste estudo, a quantidade corporal de sangue e o peso do fígado tiveram correlação baixa e negativa $(-0,13)$. Segundo Kuss et al. (2007), quanto maior a deposição de tecidos maior o aporte de sangue para a condução de nutrientes, no entanto, a correlação entre ganho de peso médio diário e quantidade de sangue neste estudo foi baixa e sem significância.

Nas Tabelas 2, 3 e 4 são descritas as médias e heteroses para os pesos absoluto e em relação ao PCVZ e PVA, respectivamente, de coração, pulmão, rins, fígado, baço e conjunto dos órgãos internos.

Os pesos absolutos dos órgãos internos não foram influenciados pela heterozigose nas gerações de cruzamento, o que está de acordo com as observações de Santos et al. (2003a), que não verificaram diferença entre animais puros e cruzados quanto ao peso absoluto dos órgãos internos. A heterose retida, no entanto, foi positiva e significativa $(14,89 \%)$ para o peso absoluto do fígado.

A superioridade numérica no peso absoluto da maioria dos órgãos internos dos animais cruzados deve-se, em parte, ao seu maior peso, pois, quando expressos em relação a $100 \mathrm{~kg}$ de PCVZe PVA, as diferenças foram negativas. A heterose foi significativa para os pesos relativos de pulmões na quarta geração $(-13,45$ e -15,54\%), e do coração $(-18,29$ e $-21,33 \%)$ e dos rins $(-14,29$ e $-15,79 \%)$ na terceira geração, respectivamente, em relação ao PCVZe PVA.

Os grupos genéticos, dentro das gerações de cruzamento, não diferiram significativamente quanto aos pesos absolutos dos órgãos. Entre os animais puros, no entanto, os novilhos Charolês apresentaram maiores pesos absolutos de coração, pulmões e fígado, assim como do conjunto dos órgãos internos. O maior peso do fígado dos animais Charolês era esperado, pois, segundo Owens et al. (1993) e 
Tabela 2 - Médias, erros-padrão e heterose para os pesos absoluto dos órgãos vitais e do conjunto destes órgãos (COI) de novilhos de diferentes grupos genéticos

Table 2 - Means, standard errors and heterosis for weight of individual organs and total weight of all internal organs (TWIO) of steers according to different genetic groups

\begin{tabular}{|c|c|c|c|c|c|c|}
\hline $\begin{array}{l}\text { Grupo genético } \\
\text { Genetic group }\end{array}$ & $\begin{array}{c}\text { Coração, kg } \\
\text { Heart, kg }\end{array}$ & $\begin{array}{l}\text { Pulmão, kg } \\
\text { Lungs, } k g\end{array}$ & $\begin{array}{l}\text { Rins, kg } \\
\text { Kidneys, } k g\end{array}$ & $\begin{array}{l}\text { Fígado, } \mathrm{kg} \\
\text { Liver, } \mathrm{kg}\end{array}$ & $\begin{array}{l}\text { Baço, kg } \\
\text { Spleen, kg }\end{array}$ & $\begin{array}{c}\text { COI, kg } \\
\text { TWIO }\end{array}$ \\
\hline Charolês (C) & $5,08 \pm 0,3^{\mathrm{a}}$ & $5,56 \pm 0,4^{\mathrm{a}}$ & $0,80 \pm 0,1$ & $5,68 \pm 0,6^{\mathrm{a}}$ & $1,55 \pm 0,2$ & $15,31 \pm 1,1^{\mathrm{a}}$ \\
\hline Nelore $(\mathrm{N})$ & $3,36 \pm 0,3^{b}$ & $3,86 \pm 0,4^{b}$ & $0,62 \pm 0,1$ & $3,79 \pm 0,5^{b}$ & $1,14 \pm 0,2$ & $10,5 \pm 0,9^{b}$ \\
\hline Média puros (Straigthbred mean) & $4,22 \pm 0,2$ & $4,71 \pm 0,3$ & $0,71 \pm 0,05$ & $4,73 \pm 0,4$ & $1,35 \pm 0,1$ & $12,91 \pm 0,7$ \\
\hline $3 / 4 \mathrm{C} 1 / 4 \mathrm{~N}$ & $4,38 \pm 0,3$ & $5,08 \pm 0,4$ & $0,82 \pm 0,1$ & $5,57 \pm 0,5$ & $1,40 \pm 0,2$ & $14,64 \pm 0,9$ \\
\hline $3 / 4 \mathrm{~N} \quad 1 / 4 \mathrm{C}$ & $4,20 \pm 0,2$ & $4,72 \pm 0,3$ & $0,80 \pm 0,1$ & $5,30 \pm 0,4$ & $1,50 \pm 0,1$ & $13,69 \pm 0,8$ \\
\hline Média G2 (G2 mean) & $4,29 \pm 0,2$ & $4,90 \pm 0,2$ & $0,81 \pm 0,04$ & $5,44 \pm 0,3$ & $1,45 \pm 0,1$ & $14,17 \pm 0,6$ \\
\hline Heterose G2, \% (G2 heterosis, \%) & 1,66 & 4,03 & 14,08 & 14,78 & 7,81 & 9,76 \\
\hline $5 / 8 \mathrm{C} 3 / 8 \mathrm{~N}$ & $3,79 \pm 0,3$ & $4,45 \pm 0,5$ & $0,71 \pm 0,1$ & $5,30 \pm 0,4$ & $1,34 \pm 0,1$ & $13,16 \pm 0,9$ \\
\hline $5 / 8 \mathrm{~N} 3 / 8 \mathrm{C}$ & $3,92 \pm 0,2$ & $5,52 \pm 0,4$ & $0,74 \pm 0,1$ & $5,47 \pm 0,3$ & $1,53 \pm 0,1$ & $14,61 \pm 0,8$ \\
\hline Média G3 (G3 mean) & $3,85 \pm 0,2$ & $4,98 \pm 0,3$ & $0,72 \pm 0,04$ & $5,38 \pm 0,2$ & $1,44 \pm 0,1$ & $13,88 \pm 0,6$ \\
\hline Heterose G3, \% (G3 heterosis, \%) & $-8,65$ & 5,84 & 2,11 & 13,73 & 6,69 & 7,59 \\
\hline $11 / 16 \mathrm{C} 5 / 16 \mathrm{~N}$ & $4,07 \pm 0,3$ & $4,83 \pm 0,3$ & $0,67 \pm 0,1$ & $5,61 \pm 0,5$ & $1,03 \pm 0,5$ & $13,53 \pm 0,9$ \\
\hline $11 / 16 \mathrm{~N} 5 / 16 \mathrm{C}$ & $3,76 \pm 0,3$ & $4,76 \pm 0,3$ & $0,74 \pm 0,1$ & $5,39 \pm 0,5$ & $2,34 \pm 0,5$ & $14,71 \pm 1,0$ \\
\hline Média G 4 (G4 mean) & $3,91 \pm 0,2$ & $4,80 \pm 0,2$ & $0,71 \pm 0,05$ & $5,50 \pm 0,4$ & $1,68 \pm 0,4$ & $14,12 \pm 0,7$ \\
\hline Heterose G4, \% (G4 heterosis) & $-7,23$ & 1,80 & $-0,70$ & 16,16 & 25,28 & 9,41 \\
\hline Heterose retida, \% (Retained heterosis, \%) & $-4,74$ & 3,89 & 5,16 & $14,89 * * *$ & 13,26 & 8,92 \\
\hline Diferença mestiços e C, \% (Crossbreds and C difference, \%) & $-20,87 * * *$ & $-11,99 *$ & $-6,67$ & $-4,23 * *$ & $-1,72$ & $-8,19 * *$ \\
\hline Diferença mestiços e N, \% (Crossbreds and $N$ difference, \%) & 19,64 & $26,77 *$ & 20,43 & $43,54 * * *$ & 33,63 & $33,87 * * *$ \\
\hline
\end{tabular}

${ }^{* *} \mathrm{P}<0,01 ;{ }^{* *} \mathrm{P}<0,05 ; \quad{ }^{*} \mathrm{P}<0,10$.

a,b Médias, na coluna, seguidas por letras diferentes na comparação entre $\mathrm{C}$ e $\mathrm{N}$ ou entre os genótipos dentro da mesma geração de cruzamento são diferentes $(\mathrm{P}<0,05)$ pelo teste $\mathrm{t}$

${ }^{* * *} P<0.01 ;{ }^{* *} P<0.05 ;{ }^{*} P<0.10$.

a,b Means, within a column followed by different letters for comparison between $C$ and $N$ or between genotypes within the same crossbreeding generation differ ( $P<0.05)$ by t test.

Tabela 3 - Médias, erros-padrão e heterose para os pesos relativos a $100 \mathrm{~kg}$ de PCVZ dos órgãos vitais e do conjunto destes órgãos (COI) de novilhos de diferentes grupos genéticos

Table 3 - Means, standard errors and heterosis for weight of individual organs and total weight of all internal organs (TWIO) expressed as $100 \mathrm{~kg}$ of empty body weight of steers according to different genetic groups

\begin{tabular}{|c|c|c|c|c|c|c|}
\hline $\begin{array}{l}\text { Grupo genético } \\
\text { Genetic group }\end{array}$ & $\begin{array}{c}\text { Coração, \% } \\
\text { Heart, \% }\end{array}$ & $\begin{array}{l}\text { Pulmões, \% } \\
\text { Lungs, \% }\end{array}$ & $\begin{array}{l}\text { Rins, \% } \\
\text { Kidneys, \% }\end{array}$ & $\begin{array}{l}\text { Fígado, \% } \\
\text { Liver, \% }\end{array}$ & $\begin{array}{l}\text { Baço, \% } \\
\text { Spleen, \% }\end{array}$ & $\begin{array}{c}\text { COI, } \% \\
\text { TWIO }\end{array}$ \\
\hline Charolês (C) & $0,47 \pm 0,03^{\mathrm{a}}$ & $1,53 \pm 0,1^{\mathrm{c}}$ & $0,22 \pm 0,02$ & $1,56 \pm 0,2$ & $0,42 \pm 0,05$ & $4,20 \pm 0,3$ \\
\hline Nelore $(\mathrm{N})$ & $0,35 \pm 0,03^{\mathrm{b}}$ & $1,22 \pm 0,1^{\mathrm{d}}$ & $0,20 \pm 0,02$ & $1,18 \pm 0,1$ & $0,37 \pm 0,05$ & $3,32 \pm 0,2$ \\
\hline Média puros (Straigthbred mean) & $0,41 \pm 0,02$ & $1,38 \pm 0,1$ & $0,21 \pm 0,01$ & $1,37 \pm 0,1$ & $0,40 \pm 0,03$ & $3,76 \pm 0,2$ \\
\hline $3 / 4 \mathrm{C} 1 / 4 \mathrm{~N}$ & $0,44 \pm 0,03^{\mathrm{a}}$ & $1,30 \pm 0,1$ & $0,21 \pm 0,02$ & $1,42 \pm 0,1$ & $0,36 \pm 0,05$ & $3,73 \pm 0,2$ \\
\hline $3 / 4 \mathrm{~N} \quad 1 / 4 \mathrm{C}$ & $0,35 \pm 0,02^{b}$ & $1,22 \pm 0,1$ & $0,20 \pm 0,01$ & $1,39 \pm 0,1$ & $0,39 \pm 0,04$ & $3,55 \pm 0,2$ \\
\hline Média G2 (G2 mean) & $0,40 \pm 0,02$ & $1,26 \pm 0,1$ & $0,21 \pm 0,01$ & $1,41 \pm 0,1$ & $0,38 \pm 0,03$ & $3,64 \pm 0,1$ \\
\hline Heterose G2, \% (G2 heterosis, \%) & $-3,66$ & $-8,36$ & $-2,38$ & 2,55 & $-5,06$ & $-3,19$ \\
\hline $5 / 8 \mathrm{C} 3 / 8 \mathrm{~N}$ & $0,34 \pm 0,02$ & $1,13 \pm 0,1$ & $0,18 \pm 0,01$ & $1,34 \pm 0,1$ & $0,34 \pm 0,03$ & $3,34 \pm 0,2$ \\
\hline $5 / 8 \mathrm{~N} 3 / 8 \mathrm{C}$ & $0,33 \pm 0,02$ & $1,39 \pm 0,1$ & $0,18 \pm 0,01$ & $1,35 \pm 0,1$ & $0,38 \pm 0,03$ & $3,62 \pm 0,2$ \\
\hline Média G3 (G3 mean) & $0,34 \pm 0,01$ & $1,26 \pm 0,1$ & $0,18 \pm 0,01$ & $1,35 \pm 0,1$ & $0,36 \pm 0,02$ & $3,48 \pm 0,2$ \\
\hline Heterose G3, \% (G3 heterosis, \%) & $-18,29 *$ & $-8,36$ & $-14,29 *$ & $-1,82$ & $-8,86$ & $-7,45$ \\
\hline $11 / 16$ C $5 / 16 \mathrm{~N}$ & $0,33 \pm 0,02$ & $1,15 \pm 0,1$ & $0,16 \pm 0,02$ & $1,34 \pm 0,1$ & $0,25 \pm 0,1^{b}$ & $3,23 \pm 0,2^{b}$ \\
\hline $11 / 16$ N 5/16 C & $0,38 \pm 0,02$ & $1,23 \pm 0,1$ & $0,19 \pm 0,02$ & $1,39 \pm 0,1$ & $0,57 \pm 0,1^{\mathrm{a}}$ & $3,77 \pm 0,2^{\mathrm{a}}$ \\
\hline Média G4 (G4 mean) & $0,36 \pm 0,01$ & $1,19 \pm 0,1$ & $0,18 \pm 0,01$ & $1,37 \pm 0,1$ & $0,41 \pm 0,1$ & $3,50 \pm 0,1$ \\
\hline Heterose G4, \% (G4 heterosis) & $-13,41$ & $-13,45^{*}$ & $-16,67$ & $-0,36$ & 3,80 & $-6,65$ \\
\hline Heterose retida, \% (Retained heterosis, \%) & $-11,79 * *$ & $-10,06$ & $-11,11$ & 0,12 & $-3,38$ & $-5,76$ \\
\hline Diferença mestiços e C, \% (Crossbreds and $C$ difference, \%) & $-23,05 * * *$ & $-19,17$ & $-15,15$ & $-12,07 * *$ & $-9,13$ & $-15,63^{*}$ \\
\hline Diferença mestiços e N, \% (Crossbreds and $N$ difference, \%) & 3,33 & 1,37 & $-6,67$ & 16,24 & 3,15 & 6,73 \\
\hline
\end{tabular}

${ }^{* * *} \mathrm{P}<0,01 ;{ }^{* *} \mathrm{P}<0,05 ; \quad{ }^{*} \mathrm{P}<0,10$.

Médias na coluna seguidas por letras diferentes na comparação entre $\mathrm{C}$ e $\mathrm{N}$ ou entre os genótipos dentro da mesma geração de cruzamento são diferentes $(\mathrm{P}<0,05(\mathrm{a}, \mathrm{b}) ; \mathrm{P}<0,10(\mathrm{c}, \mathrm{d}))$ pelo teste $\mathrm{t}$.

${ }^{* * *} P<0.01$; ${ }^{* *} P<0.05 ;{ }^{*} P<0.10$.

Means, within a column, followed by different letters for the comparison between $C$ and N or between genotypes within the same crossbreeding generation differ $\left[P<0.05\left({ }^{a}, b\right) ; P<0.10\left({ }^{c, d}\right)\right]$ by ttest. 
Tabela 4 - Médias, erros-padrão e heterose para os pesos dos órgãos vitais, em relação a $100 \mathrm{~kg}$ de PV ao abate, e do conjunto destes órgãos (COI) de novilhos de diferentes grupos genéticos

Table 4 - Means, standard errors and heterosis for weights of individual organs and total weight of all internal organs (TWIO) expressed as $100 \mathrm{~kg}$ of slaughter body weight of steers according to different genetic group

\begin{tabular}{|c|c|c|c|c|c|c|}
\hline $\begin{array}{l}\text { Grupo genético } \\
\text { Genetic group }\end{array}$ & $\begin{array}{c}\text { Coração, \% } \\
\text { Heart, \% }\end{array}$ & $\begin{array}{l}\text { Pulmão, \% } \\
\text { Lungs, \% }\end{array}$ & $\begin{array}{l}\text { Rins, \% } \\
\text { Kidneys, \% }\end{array}$ & $\begin{array}{l}\text { Fígado, \% } \\
\text { Liver, \% }\end{array}$ & $\begin{array}{l}\text { Baço, \% } \\
\text { Spleen, \% }\end{array}$ & $\begin{array}{c}\text { COI, \% } \\
\text { TWIO }\end{array}$ \\
\hline Charolês (C) & $0,43 \pm 0,03^{\mathrm{a}}$ & $1,40 \pm 0,1^{\mathrm{c}}$ & $0,20 \pm 0,02$ & $1,43 \pm 0,2$ & $0,39 \pm 0,05$ & $3,86 \pm 0,3$ \\
\hline Nelore $(\mathrm{N})$ & $0,32 \pm 0,03^{b}$ & $1,11 \pm 0,1^{\mathrm{d}}$ & $0,18 \pm 0,02$ & $1,07 \pm 0,1$ & $0,34 \pm 0,05$ & $3,02 \pm 0,2$ \\
\hline Média puros (Straigthbreds mean) & $0,37 \pm 0,02$ & $1,26 \pm 0,1$ & $0,19 \pm 0,01$ & $1,25 \pm 0,1$ & $0,36 \pm 0,03$ & $3,44 \pm 0,2$ \\
\hline $3 / 4 \mathrm{C} \quad 1 / 4 \mathrm{~N}$ & $0,41 \pm 0,03^{\mathrm{a}}$ & $1,22 \pm 0,1$ & $0,19 \pm 0,02$ & $1,33 \pm 0,1$ & $0,33 \pm 0,05$ & $3,49 \pm 0,2$ \\
\hline $3 / 4 \mathrm{~N} \quad 1 / 4 \mathrm{C}$ & $0,31 \pm 0,02^{b}$ & $1,09 \pm 0,1$ & $0,18 \pm 0,01$ & $1,23 \pm 0,1$ & $0,34 \pm 0,04$ & $3,15 \pm 0,2$ \\
\hline Média G2 (G2 mean) & $0,36 \pm 0,02$ & $1,15 \pm 0,1$ & $0,19 \pm 0,01$ & $1,28 \pm 0,1$ & $0,34 \pm 0,03$ & $3,32 \pm 0,1$ \\
\hline Heterose G2, \% (G2 heterosis, \%) & $-4,00$ & $-7,97$ & $-2,63$ & 2,40 & $-8,22$ & $-3,49$ \\
\hline $5 / 8 \mathrm{C} \quad 3 / 8 \mathrm{~N}$ & $0,30 \pm 0,02$ & $1,00 \pm 0,1$ & $0,16 \pm 0,01$ & $1,19 \pm 0,1$ & $0,30 \pm 0,03$ & $2,95 \pm 0,2$ \\
\hline $5 / 8 \mathrm{~N} 3 / 8 \mathrm{C}$ & $0,29 \pm 0,02$ & $1,22 \pm 0,1$ & $0,16 \pm 0,01$ & $1,18 \pm 0,1$ & $0,33 \pm 0,02$ & $3,17 \pm 0,2$ \\
\hline Média G3 (G3 mean) & $0,30 \pm 0,01$ & $1,11 \pm 0,1$ & $0,16 \pm 0,01$ & $1,18 \pm 0,1$ & $0,32 \pm 0,02$ & $3,06 \pm 0,2$ \\
\hline Heterose G3, \% (G3 heterosis, \%) & $-21,33^{*}$ & $-11,55$ & $-15,79^{*}$ & $-5,20$ & $-13,70$ & $-11,05$ \\
\hline $11 / 16$ C $5 / 16 \mathrm{~N}$ & $0,28 \pm 0,02^{b}$ & $0,98 \pm 0,1$ & $0,14 \pm 0,02$ & $1,15 \pm 0,1$ & $0,21 \pm 0,1^{b}$ & $2,77 \pm 0,2^{b}$ \\
\hline $11 / 16$ N 5/16 C & $0,35 \pm 0,02^{\mathrm{a}}$ & $1,14 \pm 0,1$ & $0,18 \pm 0,02$ & $1,29 \pm 0,1$ & $0,53 \pm 0,1^{\mathrm{a}}$ & $3,48 \pm 0,2^{\mathrm{a}}$ \\
\hline Média G4 (G4 mean) & $0,32 \pm 0,02$ & $1,06 \pm 0,1$ & $0,16 \pm 0,01$ & $1,22 \pm 0,1$ & $0,37 \pm 0,1$ & $3,13 \pm 0,1$ \\
\hline Heterose G4, \% (G4 heterosis) & $-16,00$ & $-15,54 *$ & $-15,79$ & $-2,40$ & 1,37 & $-9,16$ \\
\hline Heterose retida, \% (Retained heterosis, \%) & $-13,78^{* *}$ & $-11,69$ & $-11,40 *$ & $-1,73$ & $-6,85$ & $-7,90$ \\
\hline Diferença mestiços e C, \% (Crossbreds and C difference, \%) & $-24,81 * *$ & $-20,83$ & $-15,83$ & $-14,10 * *$ & $-12,82$ & $-17,92$ \\
\hline Diferença mestiços e N, \% (Crossbreds and $N$ difference, \%) & 1,04 & $-0,15$ & $-6,48$ & 14,80 & 0,00 & 4,91 \\
\hline
\end{tabular}

${ }^{* * *} \mathrm{P}<0,01 ;{ }^{* *} \mathrm{P}<0,05 ; \quad{ }^{*} \mathrm{P}<0,10$.

Médias na coluna seguidas por letras diferentes na comparação entre $\mathrm{C}$ e $\mathrm{N}$ ou entre os genótipos dentro da mesma geração de cruzamento são diferentes $\left.\mathrm{P}<0,05\left({ }^{\mathrm{a}, \mathrm{b}}\right) ; \mathrm{P}<0,10\left(^{\mathrm{c}, \mathrm{d}}\right)\right]$ pelo teste $\mathrm{t}$

${ }^{* * *} P<0.01 ;{ }^{* *} P<0.05 ;{ }^{*} P<0.10$.

Means within a column followed by different letters for the comparison between $C$ and Nor between genotypes within the same crossbreeding generation differ $[P<0.05(a, b) ; P<0.10(c, d)]$ by $t$ test.

Ferrel \& Jenkins (1998), dos órgãos vitais, o fígado é o que possui as maiores taxas metabólicas, em decorrência de sua importante participação no metabolismo dos nutrientes, estando diretamente relacionado ao consumo de nutrientes, como verificado para os animais deste genótipo, que apresentaram maior consumo de MS e ED e maior ganho de peso (Menezes \& Restle, 2005). Segundo Peron et al. (1993b), animais europeus tendem a apresentar maior massa de órgãos internos, em relação ao peso vivo, que os zebuínos. Jones et al. (1985) observaram maior peso absoluto destes órgãos em animais cruzados de raças de grande porte em comparação aos de pequeno porte, no entanto, estes autores verificaram inversão no peso relativo de fígado, pulmões e rins, o que não foi observado neste estudo (Tabelas 3 e 4). As diferenças nos pesos dos órgãos internos explicam, em parte, as variações na energia líquida de mantença entre grupos genéticos (Ferrel et al., 1976). Pacheco et al. (2005), ao comparar novilhos $5 / 8 \mathrm{C} 3 / 8 \mathrm{~N}$ ou $5 / 8 \mathrm{~N} 3 / 8 \mathrm{C}$ abatidos em idades jovem ou superjovem, observaram correlação positiva e significativa entre a exigência líquida de mantença e o peso de fígado $(r=0,57)$ e o peso de coração $(r=0,73)$.

O maior desenvolvimento do COI dos novilhos Charolês pode estar relacionado à maior seletividade do concentrado (Menezes, 2004), pois, segundo Signoretti et al. (1999) e Ribeiro et al. (2001), o desenvolvimento do COI está associado ao maior consumo de concentrado.
Os novilhos Charolês apresentaram maiores pesos relativos de coração $(\mathrm{P}<0,05)$ e pulmões $(\mathrm{P}<0,10)$ e pesos de fígado e conjunto dos órgãos internos numericamente maiores. Comparando os animais cruzados nas gerações, na segunda geração, os animais $3 / 4 \mathrm{C} 1 / 4 \mathrm{~N}$ apresentaram maior peso relativo de coração em relação aos $3 / 4 \mathrm{~N} 1 / 4 \mathrm{C}$. Na quarta geração, os animais $11 / 16 \mathrm{~N} 5 / 16 \mathrm{C}$ apresentaram maior peso de baço e do conjunto dos órgãos internos, em relação ao PCVZ, além de maior peso do coração, em relação ao PVA. Em vacas de descarte adultas, Kuss et al. (2007) verificaram maiores pesos de coração, rins e COI em vacas com maior predominância de sangue Charolês no genótipo (3/4C 1/4N e 5/8C 3/8N) em comparação àquelas com predominância de sangue Nelore (3/4N 1/4C e 5/8N 3/8C).

Os animais cruzados, em comparação aos Charolês, apresentaram coração, pulmão, fígado e COI mais leves, em peso absoluto (Tabela 2), o que também foi verificado para coração, fígado e COI quando o peso foi expresso em relação ao PCVZ (Tabela 3) e para o coração e o fígado quando o peso foi expresso em relação ao PA (Tabela 4). Os pesos de pulmão, fígado e COI dos animais cruzados, em peso absoluto, foram maiores se comparados aos dos animais Nelore. Contudo, quando os pesos foram expressos em relação ao PCVZ e ao PVA, não houve diferença.

$\mathrm{O}$ peso dos órgãos internos e o RCFCVZ correlacionaram-se negativamente $(\mathrm{P}<0,001)$, sendo 
obtidos valores de $-0,53 ;-0,54 ;-0,46$ e $-0,63$ para os pesos relativos de coração, pulmões, rins e conjunto dos órgãos internos, respectivamente.

Nas Tabelas 5, 6 e 7 constam os pesos absoluto e relativo (em relação a $100 \mathrm{~kg}$ de PCVZe $100 \mathrm{~kg}$ de PVA) de rúmen, omaso, abomaso, intestino delgado + grosso (IDG), trato gastrintestinal (TGI) e conteúdo do trato gastrintestinal (CTGI).

Não houve efeito da heterozigose no peso absoluto dos componentes do TGI nas gerações do cruzamento. A heterose foi significativa apenas para o peso absoluto do CTGI na segunda geração. Por outro lado, quando expresso em relação ao PCVZ, o peso obtido nos animais cruzados foi inferior à média encontrada nos puros: omaso $=-16,03 \%$ (segunda geração); IDG =-20,11\%; $\mathrm{TGI}=-13,10 \%$ e CTGI = $11,67 \%$ (terceira geração); rúmen $=-12,50 \% ; \mathrm{eCTGI}=-15,33 \%$ (quarta geração). A heterose retida foi de $-13,58 \%$ para IDG e $-9,86 \%$ para TGI.

Na Tabela 7, verifica-se que, ao expressar os componentes em relação ao PVA, a heterose foi negativa para omaso, TGI e rúmen, respectivamente, na segunda, terceira e quarta gerações de cruzamento. A heterose retida foi negativa para IDG e TGI

Os novilhos Charolês apresentaram, em comparação aos Nelore, maior peso absoluto de rúmen, abomaso e IDG, refletindo esta diferença no peso absoluto do TGI.
Ferreira et al. (2000) demonstraram que o peso de abomaso aumenta com o nível de concentrado na dieta, o que foi observado neste estudo, visto que os novilhos Charolês apresentaram maior seletividade pelo concentrado da dieta (Menezes, 2004).

Quando o peso dos órgãos responsáveis pela digestão foi expresso em relação ao PCVZ e ao PVA, a vantagem dos novilhos Charolês não se manteve apenas no peso do IDG. Peron et al. (1993a) observaram menores pesos do TGI em animais Nelore em relação aos taurinos. Resultados similares são reportados por Ferrel \& Jenkins (1998), que verificaram maior peso do TGI em animais Angus e Hereford em comparação aos da raça Brahman. Estes autores associaram o menor tamanho do TGI ao menor potencial de consumo das raças zebuínas, o que foi observado neste estudo (Menezes \& Restle, 2005). Galvão et al. (1991) atribuíram as diferenças no rendimento de carcaça em animais Nelore e seus mestiços com raças taurinas às variações no peso do TGI. Neste estudo, o peso do TGI afetou o rendimento de carcaça, de modo que a correlação entre estas duas variáveis foi de -0,61 $(\mathrm{P}<0,01)$. Santos et al. (2003b) observaram que foi necessário apenas $25 \%$ de sangue Nelore no cruzamento para haver diferença no peso relativo do TGI, porém, esta diferença não foi suficiente para alterar o rendimento de carcaça.

Tabela 5 - Médias, erros-padrão e heterose para os pesos absolutos de rúmen, omaso, abomaso, intestino delgado + grosso (IDG), trato gastrintestinal (TGI) e conteúdo gastrintestinal (CTGI) de novilhos de diferentes grupos genéticos

Table 5 - Means, standard errors and heterosis for weights of rumen, omasum, abomasum, small plus large intestine (SILI), total gastrointestinal tract (TGI) and gastrointestinal content (GIC) of steers according to different genetic groups

\begin{tabular}{|c|c|c|c|c|c|c|}
\hline $\begin{array}{l}\text { Grupo genético } \\
\text { Genetic group }\end{array}$ & $\begin{array}{l}\text { Rúmen, kg } \\
\text { Rumen, } k g\end{array}$ & $\begin{array}{l}\text { Omaso, } \mathrm{kg} \\
\text { Omasum, } \mathrm{kg}\end{array}$ & $\begin{array}{l}\text { Abomaso, } \mathrm{kg} \\
\text { Abomasum, } \mathrm{kg}\end{array}$ & $\begin{array}{l}\text { IDG, } \mathrm{kg} \\
\quad \text { SILI }\end{array}$ & TGI, $\mathrm{kg}$ & $\begin{array}{l}\text { CTGI, } \mathrm{kg} \\
\text { GIC }\end{array}$ \\
\hline Charolês (C) & $9,1 \pm 1,4^{\mathrm{c}}$ & $5,2 \pm 0,6$ & $3,90 \pm 0,8^{\mathrm{a}}$ & $7,4 \pm 0,8^{\mathrm{c}}$ & $25,5 \pm 2,1^{\mathrm{a}}$ & $41,3 \pm 3,5$ \\
\hline Nelore (N) & $5,6 \pm 1,2^{d}$ & $3,9 \pm 0,5$ & $1,7 \pm 0,7^{b}$ & $5,4 \pm 0,7^{d}$ & $16,6 \pm 1,9^{b}$ & $34,1 \pm 3,0$ \\
\hline Média puros (Straigthbred mean) & $7,3 \pm 0,9$ & $4,5 \pm 0,4$ & $2,8 \pm 0,5$ & $6,4 \pm 0,5$ & $21,1 \pm 1,4$ & $37,7 \pm 2,2$ \\
\hline $3 / 4 \mathrm{C} 1 / 4 \mathrm{~N}$ & $7,7 \pm 1,2$ & $4,2 \pm 0,5$ & $2,9 \pm 0,7$ & $5,9 \pm 0,7$ & $20,7 \pm 1,9$ & $47,2 \pm 3,0^{\mathrm{a}}$ \\
\hline $3 / 4 \mathrm{~N} \quad 1 / 4 \mathrm{C}$ & $10,1 \pm 1,0$ & $4,4 \pm 0,4$ & $1,9 \pm 0,5$ & $6,9 \pm 0,6$ & $23,4 \pm 1,5$ & $38,6 \pm 2,5^{b}$ \\
\hline Média G2 (G2 mean) & $8,9 \pm 0,8$ & $4,3 \pm 0,3$ & $2,4 \pm 0,4$ & $6,4 \pm 0,5$ & $22,0 \pm 1,2$ & $42,9 \pm 1,9$ \\
\hline Heterose G2, \% (G2 heterosis, \%) & 21,8 & $-4,5$ & $-14,5$ & $-0,2$ & 4,7 & $13,8^{*}$ \\
\hline $5 / 8 \mathrm{C} \quad 3 / 8 \mathrm{~N}$ & $8,9 \pm 0,9$ & $4,9 \pm 0,4$ & $2,3 \pm 0,5$ & $6,1 \pm 0,4$ & $22,1 \pm 1,3$ & $36,7 \pm 2,8$ \\
\hline $5 / 8 \mathrm{~N} 3 / 8 \mathrm{C}$ & $7,3 \quad 0,7$ & $4,8 \pm 0,4$ & $2,4 \pm 0,4$ & $5,8 \pm 0,4$ & $20,2 \pm 1,1$ & $41,8 \pm 2,4$ \\
\hline Média G3 (G3 mean) & $8,1 \pm 0,5$ & $4,9 \pm 0,3$ & $2,3 \pm 0,3$ & $6,0 \pm 0,3$ & $21,2 \pm 0,8$ & $39,2 \pm 1,8$ \\
\hline Heterose G3, \% (G3 heterosis, \%) & 10,0 & 7,1 & $-17,5$ & $-6,9$ & 0,6 & 4,1 \\
\hline $11 / 16$ C $5 / 16 \mathrm{~N}$ & $6,8 \pm 1,0$ & $4,6 \pm 0,3$ & $2,8 \pm 0,5$ & $6,9 \pm 0,5$ & $21,1 \pm 1,4$ & $36,8 \pm 2,6$ \\
\hline $11 / 16 \mathrm{~N} 5 / 16 \mathrm{C}$ & $8,4 \pm 1,2$ & $5,3 \pm 0,4$ & $3,0 \pm 0,5$ & $6,9 \pm 0,6$ & $23,6 \pm 1,6$ & $38,6 \pm 2,9$ \\
\hline Média G4 (G4 mean) & $7,6 \pm 0,8$ & $4,9 \pm 0,2$ & $2,9 \pm 0,4$ & $6,9 \pm 0,4$ & $22,4 \pm 1,1$ & $37,7 \pm 2,0$ \\
\hline Heterose G4, \% (G4 heterosis) & 3,7 & 9,5 & 3,9 & 7,7 & 6,2 & 0,04 \\
\hline Heterose retida, \% (Retained heterosis, \%) & 11,9 & 4,0 & $-9,4$ & 0,2 & 3,8 & 6,0 \\
\hline Diferença mestiços e C, \% (Crossbreds and C difference, \%) & $-9,5$ & $-9,5^{*}$ & $-34,9 * *$ & $-13,0 *$ & $-14,4 * *$ & $-3,2$ \\
\hline Diferença mestiços e $\mathrm{N}, \%$ (Crossbreds and $N$ difference, \%) & 46,4 & $22,3 *$ & $49,3 *$ & 18,2 & $31,8 * *$ & $17,1^{*}$ \\
\hline
\end{tabular}

${ }^{* *} \mathrm{P}<0,01 ;{ }^{*} \mathrm{P}<0,10$.

Médias na coluna seguidas por letras diferentes na comparação entre $\mathrm{C}$ e $\mathrm{N}$ ou entre os genótipos dentro da mesma geração de cruzamento são diferentes $(\mathrm{P}<0,05(\mathrm{a}, \mathrm{b}) ; \mathrm{P}<0,10(\mathrm{c}, \mathrm{d}))$ pelo teste $\mathrm{t}$

${ }^{* *} P<0.01 ;{ }^{*} P<0.10$

Means within a column followed by different letters for comparison between $C$ and $N$ or between genotypes within the same crossbreeding generation differ $(P<0.05(a, b) ; P<0.10(c, d))$ by $t$ test. 
Tabela 6 - Médias, erros-padrão e heterose para os pesos relativos (em relação a $100 \mathrm{~kg}$ de PCVZ) do rúmen, omaso, abomaso, intestino delgado + grosso (IDG), trato gastrintestinal (TGI) e conteúdo gastrintestinal (CTGI) de novilhos de diferentes grupos genéticos

Table 6 - Means, standard errors and heterosis for weights of rumen, omasum, abomasum, small plus large intestine (SILI), total gastrointestinal tract (TGI) and gastrointestinal content (GIC) expressed as $100 \mathrm{~kg}$ of empty body weight of steers according to different genetic groups

\begin{tabular}{|c|c|c|c|c|c|c|}
\hline $\begin{array}{l}\text { Grupo genético } \\
\text { Genetic group }\end{array}$ & $\begin{array}{c}\text { Rúmen, \% } \\
\text { Rumen, \% }\end{array}$ & $\begin{array}{l}\text { Omaso, \% } \\
\text { Omasum, \% }\end{array}$ & $\begin{array}{l}\text { Abomaso, } \% \\
\text { Abomasum, \% }\end{array}$ & $\begin{array}{l}\text { IDG, \% } \\
\text { SILI, \% }\end{array}$ & TGI, \% & $\begin{array}{l}\text { CTGI, \% } \\
\text { GIC, \% }\end{array}$ \\
\hline Charolês (C) & $2,46 \pm 0,4^{\mathrm{a}}$ & $1,42 \pm 0,1$ & $1,10 \pm 0,2^{\mathrm{a}}$ & $2,02 \pm 2,0$ & $7,00 \pm 0,5^{\mathrm{a}}$ & $11,36 \pm 0,9$ \\
\hline Nelore $(\mathrm{N})$ & $1,78 \pm 0,3^{b}$ & $1,20 \pm 0,1$ & $0,52 \pm 0,2^{b}$ & $1,71 \pm 1,7$ & $5,21 \pm 0,4^{b}$ & $10,75 \pm 0,8$ \\
\hline Média puros (Straigthbred mean) & $2,12 \pm 0,2$ & $1,31 \pm 0,1$ & $0,81 \pm 0,1$ & $1,87 \pm 0,1$ & $6,11 \pm 0,3$ & $11,06 \pm 0,6$ \\
\hline $3 / 4 \mathrm{C} \quad 1 / 4 \mathrm{~N}$ & $1,95 \pm 0,3$ & $1,08 \pm 0,1$ & $0,75 \pm 0,2$ & $1,47 \pm 1,5$ & $5,25 \pm 0,4$ & $12,02 \pm 0,8^{\mathrm{d}}$ \\
\hline $3 / 4 \mathrm{~N} \quad 1 / 4 \mathrm{C}$ & $2,65 \pm 0,3$ & $1,12 \pm 0,1$ & $0,48 \pm 0,1$ & $1,78 \pm 1,8$ & $6,03 \pm 0,3$ & $9,98 \pm 0,6^{\mathrm{c}}$ \\
\hline Média G2 (G2 mean) & $2,30 \pm 0,2$ & $1,10 \pm 0,1$ & $0,62 \pm 0,1$ & $1,62 \pm 0,1$ & $5,64 \pm 0,3$ & $11,00 \pm 0,5$ \\
\hline Heterose G2, \% (G2 heterosis, \%) & 8,49 & $-16,03 *$ & $-24,07$ & $-12,87$ & $-7,62$ & $-0,50$ \\
\hline $5 / 8 \mathrm{C} 3 / 8 \mathrm{~N}$ & $2,22 \pm 0,2^{\mathrm{c}}$ & $1,25 \pm 0,1$ & $0,60 \pm 0,1$ & $1,54 \pm 0,1$ & $5,62 \pm 0,3$ & $9,34 \pm 0,6$ \\
\hline $5 / 8 \mathrm{~N} \quad 3 / 8 \mathrm{C}$ & $1,79 \pm 0,2^{\mathrm{d}}$ & $1,18 \pm 0,1$ & $0,58 \pm 0,1$ & $1,44 \pm 0,1$ & $4,99 \pm 0,2$ & $10,19 \pm 0,5$ \\
\hline Média G3 (G3 mean) & $2,01 \pm 0,1$ & $1,21 \pm 0,1$ & $0,59 \pm 0,1$ & $1,49 \pm 0,1$ & $5,30 \pm 0,2$ & $9,77 \pm 0,4$ \\
\hline Heterose G3, \% (G3 heterosis, \%) & $-5,42$ & $-7,25$ & $-27,16$ & $-20,11 * *$ & $-13,10 * *$ & $-11,67 *$ \\
\hline $11 / 16$ C $5 / 16 \mathrm{~N}$ & $1,61 \pm 0,2$ & $1,11 \pm 0,1^{b}$ & $0,69 \pm 0,1$ & $1,65 \pm 0,2$ & $5,06 \pm 0,3^{\mathrm{d}}$ & $8,78 \pm 0,6$ \\
\hline $11 / 16 \mathrm{~N} 5 / 16 \mathrm{C}$ & $2,10 \pm 0,3$ & $1,38 \pm 0,1^{\mathrm{a}}$ & $0,80 \pm 0,1$ & $1,79 \pm 0,2$ & $6,07 \pm 0,4^{\mathrm{c}}$ & $9,94 \pm 0,7$ \\
\hline Média G4 (G4 mean) & $1,86 \pm 0,2$ & $1,24 \pm 0,1$ & $0,75 \pm 0,1$ & $1,72 \pm 0,1$ & $5,56 \pm 0,3$ & $9,36 \pm 0,5$ \\
\hline Heterose G4, \% (G4 heterosis) & $-12,50 * * *$ & $-4,96$ & $-8,02$ & $-7,77$ & $-8,85$ & $-15,33 *$ \\
\hline Heterose retida, \% (Retained heterosis, \%) & $-3,14$ & $-9,41$ & $-19,75$ & $-13,58 * *$ & $-9,86 *$ & $-9,17$ \\
\hline Diferença mestiços e C, \% (Crossbreds and C difference, \%) & $-16,53$ & $-16,43$ & $-40,91 *$ & $-20,21$ & $-21,38 * *$ & $-11,61$ \\
\hline Diferença mestiços e N, \% (Crossbreds and $N$ difference, \%) & 15,36 & $-1,11$ & 25,00 & $-5,75$ & 5,63 & $-6,59$ \\
\hline
\end{tabular}

${ }^{* *} \mathrm{P}<0,01 ;{ }^{*} \mathrm{P}<0,05 ; \quad{ }^{*} \mathrm{P}<0,10$.

Médias na coluna seguidas por letras diferentes na comparação entre $\mathrm{C}$ e $\mathrm{N}$ ou entre os genótipos dentro da mesma geração de cruzamento são diferentes $\left(P<0,05\left({ }^{a, b}\right) ; P<0,10(\mathrm{c}, \mathrm{d})\right)$ pelo teste $t$.

${ }^{* \star *} P<0.01 ;{ }^{* *} P<0.05 ;{ }^{*} P<0.10$.

Means, within a column, followed by different letters for comparison between $C$ and $N$ or between genotypes within the same crossbreeding generation differ $[P<0.05(a, b) ; P<0.10(c, d)]$ by $t$ test.

Tabela 7 - Médias, erros-padrão e heterose para os pesos relativos (em relação a $100 \mathrm{~kg}$ de PVA) de rúmen, omaso, abomaso, intestino delgado + grosso (IDG), trato gastrintestinal (TGI) e conteúdo gastrintestinal (CTGI) de novilhos de diferentes grupos genéticos

Table 7 - Means, standard errors and heterosis for weights of rumen, omasum, abomasum, small plus large intestine (SILI), total gastrointestinal tract (TGI) and gastrointestinal content (GIC) expressed as $100 \mathrm{~kg}$ of slaughter body weight of steers according to different genetic groups

\begin{tabular}{|c|c|c|c|c|c|c|}
\hline $\begin{array}{l}\text { Grupo genético } \\
\text { Genetic group }\end{array}$ & $\begin{array}{l}\text { Rúmen, \% } \\
\text { Rumen, \% }\end{array}$ & $\begin{array}{l}\text { Omaso, \% } \\
\text { Omasum, \% }\end{array}$ & $\begin{array}{l}\text { Abomaso, \% } \\
\text { Abomasum, \% }\end{array}$ & $\begin{array}{l}\text { IDG, \% } \\
\text { SILI, \% }\end{array}$ & TGI, \% & $\begin{array}{c}\text { CTGI, \% } \\
\text { GIC, \% }\end{array}$ \\
\hline Charolês (C) & $2,25 \pm 0,4^{\mathrm{a}}$ & $1,31 \pm 0,1$ & $1,02 \pm 0,2^{\mathrm{a}}$ & $1,85 \pm 0,2$ & $6,43 \pm 0,5^{\mathrm{a}}$ & $10,46 \pm 0,9$ \\
\hline Nelore $(\mathrm{N})$ & $1,63 \pm 0,3^{b}$ & $1,09 \pm 0,1$ & $0,48 \pm 0,2^{b}$ & $1,57 \pm 0,2$ & $4,77 \pm 0,4^{b}$ & $9,80 \pm 0,8$ \\
\hline Média puros (Straigthbreds mean) & $1,94 \pm 0,2$ & $1,20 \pm 0,1$ & $0,75 \pm 0,1$ & $1,71 \pm 0,1$ & $5,60 \pm 0,3$ & $10,13 \pm 0,6$ \\
\hline $3 / 4 \mathrm{C} 1 / 4 \mathrm{~N}$ & $1,83 \pm 0,3$ & $1,00 \pm 0,1$ & $0,70 \pm 0,2$ & $1,38 \pm 0,2$ & $4,91 \pm 0,4$ & $11,23 \pm 0,8^{\mathrm{a}}$ \\
\hline $3 / 4 \mathrm{~N} \quad 1 / 4 \mathrm{C}$ & $2,35 \pm 0,3$ & $1,00 \pm 0,1$ & $0,42 \pm 0,1$ & $1,58 \pm 0,1$ & $5,35 \pm 0,3$ & $8,87 \pm 0,6^{b}$ \\
\hline Média G2 (G2 mean) & $2,09 \pm 0,2$ & $1,00 \pm 0,1$ & $0,56 \pm 0,1$ & $1,48 \pm 0,1$ & $5,13 \pm 0,3$ & $10,04 \pm 0,5$ \\
\hline Heterose G2, \% (G2 heterosis, \%) & 7,73 & $-16,67 *$ & $-25,33$ & $-13,45$ & $-8,39$ & $-0,79$ \\
\hline $5 / 8 \mathrm{C} 3 / 8 \mathrm{~N}$ & $1,97 \pm 0,2$ & $1,11 \pm 0,1$ & $0,54 \pm 0,1$ & $1,36 \pm 0,1$ & $4,97 \pm 0,3$ & $8,27 \pm 0,6$ \\
\hline $5 / 8 \mathrm{~N} 3 / 8 \mathrm{C}$ & $1,55 \pm 0,2$ & $1,03 \pm 0,1$ & $0,50 \pm 0,1$ & $1,25 \pm 0,1$ & $4,33 \pm 0,2$ & $8,85 \pm 0,5$ \\
\hline Média G3 (G3 mean) & $1,76 \pm 0,1$ & $1,07 \pm 0,1$ & $0,52 \pm 0,1$ & $1,30 \pm 0,1$ & $4,65 \pm 0,2$ & $8,56 \pm 0,4$ \\
\hline Heterose G3, \% (G3 heterosis, \%) & $-9,28$ & $-10,83$ & $-30,67$ & $-23,68$ & $-16,96 * *$ & $-15,50$ \\
\hline $11 / 16$ C $5 / 16 \mathrm{~N}$ & $1,37 \pm 0,2^{\mathrm{d}}$ & $0,95 \pm 0,1^{b}$ & $0,61 \pm 0,1$ & $1,42 \pm 0,2$ & $4,35 \pm 0,3^{b}$ & $7,55 \pm 0,7$ \\
\hline $11 / 16 \mathrm{~N} 5 / 16 \mathrm{C}$ & $1,94 \pm 0,3^{\mathrm{c}}$ & $1,27 \pm 0,1^{\mathrm{a}}$ & $0,75 \pm 0,1$ & $1,66 \pm 0,2$ & $5,61 \pm 0,4^{\mathrm{a}}$ & $9,19 \pm 0,8$ \\
\hline Média G4 (G4 mean) & $1,65 \pm 0,2$ & $1,11 \pm 0,1$ & $0,68 \pm 0,1$ & $1,54 \pm 0,1$ & $4,98 \pm 0,3$ & $8,37 \pm 0,5$ \\
\hline Heterose G4, \% (G4 heterosis) & $-14,69 * *$ & $-7,50$ & $-9,33$ & $-9,94$ & $-11,07$ & $-17,37$ \\
\hline Heterose retida, \% (Retained heterosis, \%) & $-5,41$ & $-11,67$ & $-21,78$ & $-15,69 * *$ & $-12,14 *$ & $-11,22$ \\
\hline Diferença mestiços e C, \% (Crossbreds and $C$ difference, \%) & $-18,44$ & $-19,08$ & $-42,48 * * *$ & $-22,07$ & $-23,48 * *$ & $-14,02$ \\
\hline Diferença mestiços e N, \% (Crossbreds and $N$ difference, \%) & 12,58 & $-2,75$ & 22,22 & $-8,17$ & 3,14 & $-8,23$ \\
\hline
\end{tabular}

${ }^{* * *} \mathrm{P}<0,01 ;{ }^{* *} \mathrm{P}<0,05 ; \quad{ }^{*} \mathrm{P}<0,10$.

Médias, na coluna, seguidas por letras diferentes na comparação entre $\mathrm{C}$ e $\mathrm{N}$ ou entre os genótipos dentro da mesma geração de cruzamento são diferentes $\left(\mathrm{P}<0,05\left({ }^{a, b}\right) ; P<0,10\left({ }^{c, d}\right)\right)$ pelo teste t.

${ }^{* * *} P<0.01 ;{ }^{* *} P<0.05 ;{ }^{*} P<0.10$.

Means, within a column, followed by different letters for comparison between $C$ and $N$, or between genotypes within the same crossbreeding generation differ $\left[P<0.05\left({ }^{a, b}\right) ; P<0.10\left({ }^{c, d}\right)\right]$ by $t$ test. 
O CTGI relativo ao PVA variou entre $8,78 \%$ $(11 / 16 \mathrm{C} 5 / 16 \mathrm{~N})$ e $12,02 \%$ (3/4C 1/4N). Segundo Rohr \& Daenicke (1984), o CTGI pode variar de 5 a $25 \%$ do PV, em decorrência de fatores como raça, peso e estado fisiológico do animal, tipo de dieta e número de horas em jejum (Véras et al., 2001). O CTGI não variou entre os animais puros, observando-se variação $(\mathrm{P}<0,05)$ apenas na $\mathrm{G} 2$ (os animais 3/4N 1/4C apresentaram 18,22\% menos conteúdo absoluto que os $3 / 4 \mathrm{C} 1 / 4 \mathrm{~N}$ ). A diferença no peso absoluto de CTGI em favor dos $3 / 4 \mathrm{C} 1 / 4 \mathrm{~N}$ se manteve quando o peso foi expresso em relação a $100 \mathrm{~kg}$ de PCVZ ou a $100 \mathrm{~kg}$ de PA. Lana et al. (1992) constataram que o CTGI diminui com o aumento no PCVZ. Esses autores não encontraram diferenças significativas nos diferentes grupos genéticos estudados e aconselharam o uso de uma equação geral para todos os genótipos para estimativa do PCVZ. Neste estudo, houve relação entre estas duas variáveis, observando-se correlação de -0,17 (P<0,05). A correlação entre o CTGI e o rendimento de carcaça fria, apesar de negativa, foi baixa e não significativa.

\section{Conclusões}

O cruzamento rotativo das raças Charolês e Nelore resultou em novilhos cruzados superiores aos puros quanto ao peso de corpo vazio e ao rendimento de carcaça estimado em relação ao peso de corpo vazio.

A heterose retida foi positiva para características importantes como peso de corpo vazio e rendimento de carcaça em relação ao peso de corpo vazio e negativa (característica desejável) para a quantidade de sangue e para os pesos de coração, intestino delgado + grosso e trato gastrintestinal expressos em relação ao peso de corpo vazio.

Novilhos Charolês atingiram maiores pesos de corpo vazio e valores superiores para a maioria dos componentes quando comparados aos Nelore, principais causas do maior rendimento de carcaça dos novilhos Nelore.

\section{Literatura Citada}

CATON, J.S.; DHUYVETTER, D.V. Influence of energy supplementation on grazing ruminants: requirements and responses. Journal of Animal Science, v.75, p.533-542, 1997

FERREIRA, M.A.; VALADARES FILHO, S.C.; MUNIZ, E.B. et al. Características das carcaças, biometria do trato gastrintestinal, tamanho dos órgãos internos e conteúdo gastrintestinal de bovinos F1 Simental x Nelore alimentados com dietas contendo vários níveis de concentrado. Revista Brasileira de Zootecnia, v.29, n.4, p.1174-1182, 2000

FERREL, C.L.; GARRET, W.N.; HINMAN, N. Estimation of body composition in pregnant and non-pregnant heifers. Journal of Animal Science, v.42, n.5, p.1158-1166, 1976
FERREL, C.L.; JENKINS, T.G. Body composition and energy utilization by steers of diverse genotypes fed a high-concentrate diet during the finishing period: Angus, Boran, Brahman, Hereford and Tuli Sires. Journal of Animal Science, v.76, n.2, p.647-657, 1998

GALVÃO, J.G.; FONTES, C.A.A.; PIRES, C.C. et al. Características e composição da carcaça de bovinos não castrados, abatidos em três estágios de maturidade (estudo II) de três grupos raciais. Revista da Sociedade Brasileira de Zootecnia, v.20, n.5, p.502-512, 1991

JONES, S.M.D.; ROMPALA, R.E.; JEREMIAH, L.E. Growth and composition of the empty body in steers of different maturity types fed concentrate or forage diets. Journal of Animal Science, v.60, n.2, p.427-433, 1985

KUSS, F.; RESTLE, J. BRONDANI, I.L. et al. Órgãos vitais e trato gastrintestinal de vacas de descarte mestiças charolês - nelore abatidas com pesos distintos. Revista Brasileira de Zootecnia, 2007 (no prelo)

LANA, R.P.; FONTES, C.A.; PERON, A.J. et al. Conteúdo do trato gastrintestinal (digesta) e sua relação com o peso corporal e ganho de peso, em novilhos de cinco grupos raciais e bovinos inteiros, Revista Brasileira de Zootecnia, v.21, n.3, p.510-517, 1992.

LUNT, D.K.; BYERS, F.M.; GREENE, L.W. et al. Effects of breed, diet, and growth rate on vital organ mass in growing and finishing beef steers. Journal of Animal Science, v.63, n.1, p.70-71, 1986 (suppl. 1).

MENEZES, L.F.G. Avaliação de novilhos das gerações avançadas do cruzamento rotativo Charolês - Nelore. Santa Maria: Universidade Federal de Santa Maria, 2004. 150p. Dissertação (Mestrado em Zootecnia) - Universidade Federal de Santa Maria, 2004

MENEZES, L.F.G.; RESTLE, J. Desempenho de novilhos de gerações avançadas do cruzamento alternado entre as raças Charolês e Nelore, terminados em confinamento. Revista Brasileira de Zootecnia, v.34, n.6, p.1927-1937, 2005.

NATIONAL RESEARCH COUNCIL - NRC. Nutrient requirements of beef cattle. 7.ed. Washington, D.C.: National Academy of Sciences, 1996. 232p

OWENS, F.N.; DONALD, R.G.; SECRIST, D.S. et al. Review of some aspects of growth and development of feedlot cattle. Journal of Animal Science, v.73, n.6, p.3152-3172, 1995.

OWENS, F.N.; DUBESKI, P.; HANSON, C.F. Factors that alter the growth and development of ruminants. Journal of Animal Science, v.71, n.11, p.3138-3150, 1993

PACHECO, P.S.; RESTLE, J.; SILVA, J.H.S. et al. Características das partes do corpo não-integrantes da carcaça de novilhos jovens e superjovens de diferentes grupos genéticos. Revista Brasileira de Zootecnia, v.34, n.5, p.1678-1690, 2005

PERON, A.J.; FONTES, C.A.; LANA, R.P. et al. Rendimento de carcaça e de seus cortes básicos e área corporal de bovinos de cinco grupos genéticos, submetidos a alimentação restrita e "ad libitum". Revista da Sociedade Brasileira de Zootecnia, v.22, n.2, p.238-247, 1993a

PERON, A.J.; FONTES, C.A.A.; LANA, R.P. et al. Tamanho de órgãos internos e distribuição da gordura corporal em novilhos de cinco grupos genéticos, submetidos a alimentação restrita e ad libitum. Revista Brasileira de Zootecnia, v.22, n.5, p.813-819, 1993b

RESTLE, J.; VAZ, F.N.; QUADROS, A.R.B. et al. Características de carcaça e da carne de novilhos de diferentes genótipos de Hereford x Nelore. Revista Brasileira de Zootecnia, v. 28 , n.6, p.1245-1251, 1999.

RESTLE, J.; MENEZES, L.F.G.; ARBOITTE, M.Z. et al. Características das partes não-integrante da carcaça de novilhos 5/6 Nelore 3/8 Charolês abatidos em três estádios de desenvolvimento. Revista Brasileira de Zootecnia, v.34, n.4, p.1339-1348, 2005.

RIBEIRO, T.R.; PEREIRA, J.C.; LEÃO, M.I. et al. Tamanho de órgãos e vísceras de bezerros holandeses, para a produção de 
vitelos recebendo dietas com diferentes níveis de concentrado. Revista Brasileira de Zootecnia, v.30, n.6, p.2163-2168, 2001 (supl.)

ROHR, K.; DAENICKE, R. Nutritional effects on the distribution of live weight as gastrintestinal tract fill and tissue components in growing cattle. Journal of Animal Science, v. 58, n.3, p.753-765, 1984.

SANTOS, A.P.; BRONDANI, I.L.; RESTLE, J. et al. Influência do grupo genético e da dieta alimentar no peso do corpo vazio e órgãos vitais de novilhos superprecoce. In: REUNIÃO ANUAL DA SOCIEDADE BRASILEIRA DE ZOOTECNIA, 40., 2003, Santa Maria. Anais... Santa Maria:Sociedade Brasileira de Zootecnia, 2003a. (CD-ROM).

SANTOS, A.P.; RESTLE, J.; PASCOAL, L.L. et al. Influência do grupo genético e da dieta alimentar no peso do corpo vazio e trato gastrintestinal de novilhos superprecoce. In: In: REUNIÃO ANUAL DA SOCIEDADE BRASILEIRA DE ZOOTECNIA, 40., 2003, Santa Maria. Anais... Santa Maria: Sociedade Brasileira de Zootecnia, 2003b. (CD-ROM).

STATISTICAL ANALYSIS SYSTEM - SAS. SAS'S user's guide. SAS for Windows. Cary: 1997. 46p.
SIGNORETTI, R.D.; ARAÚJO, G.G.L.; SILVA, J.F.C. et al. Características quantitativas das partes do corpo não integrantes da carcaça animal e desenvolvimento do trato gastrintestinal de bezerros da raça holandesa alimentados com dietas contendo quatro níveis de concentrado. Revista Brasileira de Zootecnia, v.28, n.4, p.875-882, 1999.

SMITH, N.E.; BALDWIN, R.L. Effects of breed, pregnancy and lactation on weight of organs and tissues in dairy cattle. Journal of Dairy Science, v.57, n.4, p.1055-1065, 1973.

SOLIS, J.C.; BYERS, F.M.; SCHELLING, G.T. et al. Maintenance requirements and energetic efficiency of cows of different breed types. Journal of Animal Science, v.66, p.764-773, 1988.

VÉRAS, A.S.C.; VALADARES FILHO, S.C.; SILVA, J.F.C. et al. Efeito do nível de concentrado sobre o peso dos órgãos internos e do conteúdo gastrintestinal de bovinos Nelore não castrados. Revista Brasileira de Zootecnia v.30, n.3, p.1120-1126, 2001 (supl. 1). 